www.volsu.ru

DOI: https://doi.org/10.15688/jvolsu3.2017.2.5

UDC 332.1

LBC 65.290

\title{
ASSESSMENT OF FUNCTIONING OF REGIONAL INFRASTRUCTURE OF BUSINESS SUPPORT: QUANTITATIVE ASPECT
}

\author{
Aleksandr M. Peykov \\ Tambov State University named after G.R. Derzhavin, Tambov, Russian Federation \\ Yana Yu. Radyukova \\ Tambov State University named after G.R. Derzhavin, Tambov, Russian Federation \\ Elena A. Kolesnichenko \\ Tambov State University named after G.R. Derzhavin, Tambov, Russian Federation
}

\begin{abstract}
The authors pay attention to substantial aspects of the concept "regional infrastructure of business support", including the focus on territorial and functional aspects. The article aims to evaluate the effectiveness of regional infrastructure of entrepreneurial activity support. The authors suggest that effectiveness of entrepreneurial activity depends on qualitative parameters of infrastructure provision. The analysis of distribution of the indicators characterizing the level of business development in Russian regions which was carried out in the early research showed high extent of their differentiation that predetermined the need of using the typology of territories. To check the hypothesis of dependence of effectiveness of entrepreneurial activity in the regions on qualitative parameters of infrastructure provision on the basis of carrying out typology of territories nonparametric methods of an assessment of interrelation are also used. The authors assess the influence of quantity of infrastructure facilities on activity of enterprise structures. As a result of calculations, the authors confirm the hypothesis and make conclusion that the high-quality rendering of services has a key influence on the development of business sector in Russian regions. In these conditions even in the presence of sufficient number of objects of entrepreneurial activity support in the regions, the level of business development is still low that testifies to the need of high-quality transformations for system of infrastructure providing an entrepreneurial activity.
\end{abstract}

Key words: entrepreneurship, system of business support, region, regional infrastructure, effectiveness

\section{ОЦЕНКА ФУНКЦИОНИРОВАНИЯ РЕГИОНАЛЬНОЙ ИНФРАСТРУКТУРЫ ПОДДЕРЖКИ ПРЕДПРИНИМАТЕЛЬСТВА: КОЛИЧЕСТВЕННЫЙ АСПЕКТ}

\author{
Александр Михайлович Пейков \\ Тамбовский государственный университет им. Г.Р. Державина, г. Тамбов, Российская Федерация \\ Яна Юрьевна Радюкова \\ Тамбовский государственный университет им. Г.Р. Державина, г. Тамбов, Российская Федерация \\ Елена Александровна Колесниченко \\ Тамбовский государственный университет им. Г.Р. Державина, г. Тамбов, Российская Федерация
}


Аннотация. В статье авторами уделено внимание содержательным аспектам понятия «региональная инфраструктура поддержки предпринимательства», в том числе акцентированное внимание на территориальном и функциональном аспектам. В качестве цели было определено проведение оценки результативности функционировании региональной инфраструктуры поддержки предпринимательской деятельности. Авторами выдвинуто предположение, что результативность предпринимательской деятельности зависит от качественных параметров инфраструктурного обеспечения. Проведенный в ранних исследованиях анализ распределения показателей, характеризующих уровень развития предпринимательства в регионах России, показал высокую степень их дифференциации, что предопределило необходимость использования типологии территорий. Для проверки гипотезы о зависимости результативности предпринимательской деятельности в регионах от качественных параметров инфраструктурного обеспечения на основе проведения типологии территорий и использованы непараметрические методы оценки взаимосвязи. Авторами проведена оценка влияния количества объектов инфраструктуры на деятельность предпринимательских структур. В результате расчетов выдвинутая гипотеза подтверждена и сделан вывод, что на показатели развития предпринимательского сектора в регионах России оказывает ключевое влияние не численное значение инфраструктурных объектов, а их качественное предоставление услуг. В сложившихся условиях даже при наличии достаточного количества объектов поддержки предпринимательской деятельности в регионах не приходится говорить о высоком уровне развития предпринимательства, что свидетельствует о необходимости качественных преобразований в системе инфраструктурного обеспечения предпринимательской деятельности.

Ключевые слова: предпринимательство, система поддержки предпринимательства, регион, региональная инфраструктура, оценка результативности.

\section{Вводная часть}

Региональная экономика не может существовать без эффективно функционирующей инфраструктуры. В то же время и предпринимательская деятельность нуждается в постоянной поддержке со стороны инфраструктурных объектов [2].

В данной статье авторами совмещено два понятия и дана им единая содержательная интерпретация. Отметим, что исследуемый термин «региональная инфраструктура поддержки предпринимательства» включает в себя две разные по экономическому содержанию категории. Из множества имеющихся определений данных понятий и перечня объектов инфраструктуры, указанных в Федеральном законе 209-Ф3 ${ }^{1}$, следует, что в сравнении с общим понятием «инфраструктура», с одной стороны, «инфраструктура поддержки предпринимательской деятельности» - более узкая, так как абстрагируется от выполнения социальной, экологической и других функций, но в более широком смысле к инфраструктуре поддержки предпринимательской деятельности следует относить транспортную, экологическую и т. д., хотя при рассмотрении состава объектов авторы чаще всего акцентируют внимание на более узком понимании понятия «поддержка». С другой стороны, данное понятие является более широким по отношению к понятию «реги- он», поскольку в некоторых случаях не имеет территориальной принадлежности.

Таким образом, систематизируя понятия «региональная инфраструктура» и «инфраструктура поддержки предпринимательства» отметим следующее.

Во-первых, применительно к понятию «региональная инфраструктура поддержки предпринимательства» расширим состав входящих в нее объектов. Причем все объекты классифицируем на два вида: обслуживающие (региональные объекты инфраструктуры, обеспечивающие бесперебойное ведение предпринимательской деятельности) и поддерживающие (обеспечивающие финансовую и гарантийную поддержку).

Во-вторых, чтобы разграничить понятия «инфраструктура поддержки предпринимательской деятельности» и «региональная инфраструктура поддержки предпринимательства» необходимо ввести территориальную принадлежность объекта к какому-либо региону по принципу потребления услуг. Иными словами, если объект инфраструктуры в равных условиях оказывает поддержку предпринимательским структурам из различных регионов, его нельзя считать региональным.

Как показывает опыт, предпринимательская деятельность успешно развивается, если в регионах создана и функционирует действенная инфраструктура [5]. Таким образом, ак- 
туальной становится задача количественной оценки результативности функционирования региональной инфраструктуры поддержки предпринимательства.

\section{Данные о методике исследования}

В качестве методической основы исследования авторами использована в первую очередь типология регионов. Для проведения группировки регионов реализованы следующие этапы:

- определен перечень показателей для проведения типологии;

- проведен расчет среднего значения по каждому из выбранных показателей;

- проведено сопоставление каждого значения со средним: в случае превышения присвоен знак «+», в остальных случаях - «-»;

- проанализировано количество имеющихся знаков. Если имеют место только положительные знаки, то уровень развития «очень высокий», если один «-», то высокий, и т. д. «средний», «низкий» и «очень низкий».

Во-вторых, непараметрические методы оценки взаимосвязи численности объектов инфраструктурного обеспечения предпринимательской деятельности в регионах и показателей результативности предпринимательской деятельности. Авторами использованы коэффициенты взаимной сопряженности Пирсона-Чупрова, которые вычисляются по следующим формулам [1]:

$$
\begin{gathered}
K_{\Pi}=\sqrt{\frac{\varphi^{2}}{1+\varphi^{2}}}, \\
K_{\mathrm{\Psi}}=\sqrt{\frac{\varphi^{2}}{\sqrt{\left(K_{1}-1\right)\left(K_{2}-1\right)}}},
\end{gathered}
$$

где $\varphi^{2}$ - показатель взаимной сопряженности; $\varphi^{2}-$ определяется как сумма отношений квадратов частот каждой клетки таблицы к произведению итоговых частот соответствующего столбца и строки минус 1;

$$
\varphi^{2}=\sum \frac{n_{x y}^{2}}{n_{x} n_{y}}-1,
$$

$K_{1}$ - число значений (групп) первого признака; $K_{2}-$ число значений (групп) второго признака.

Чем ближе величины $K_{\Pi}$ и $K_{\mathrm{\Psi}}$ к 1 , тем теснее связь.
Для расчетов используется вспомогательная таблица 1.

Таблица 1

Вспомогательная таблица для расчета коэффициента взаимной сопряженности

\begin{tabular}{|c|c|c|c|c|}
\hline $\mathrm{y}$ & 1 & 2 & 3 & Всего \\
\hline 1 & $\ldots$ & $\ldots$ & $\mathrm{n}_{\mathrm{xy}}$ & $\mathrm{n}_{\mathrm{x}}$ \\
\hline 2 & $\ldots$ & $\ldots$ & & $\mathrm{n}_{\mathrm{x}}$ \\
\hline 3 & $\ldots$ & $\ldots$ & & $\mathrm{n}_{\mathrm{x}}$ \\
\hline Итого & $\mathrm{n}_{\mathrm{y}}$ & $\mathrm{n}_{\mathrm{y}}$ & $\mathrm{n}_{\mathrm{y}}$ & $\mathrm{n}$ \\
\hline
\end{tabular}

В данной связи решена задача «свертывания» показателей, характеризующих результаты деятельности предпринимательства в один.

\section{Экспериментальная часть}

Для оценки результативности выбраны следующие показатели из доступных по всем регионам и размещенные на сайте Федеральной службы статистики [4]:

- инвестиции в основной капитал (млн руб.);

- оборот организаций (млрд руб.);

- число предприятий и организаций (тыс.);

- сальдированный финансовый результат (млн руб.).

На основе представленных сравнительных показателей произведем группировку регионов. При условии, что все четыре показателя по региону принимают значения выше среднего по стране, следует говорить о «высоком» уровне развития предпринимательства на основе анализа основных показателей развития предпринимательства в регионе. Если имеет место три превышения среднего значения из четырех, то речь идет о «достаточном» уровне развития на основе оценки показателей развития предпринимательства, если о двух о «среднем» уровне развития предпринимательства; при наличии всего одного превышения следует говорить о «низком» уровне развития предпринимательства. Если же ни один из показателей не превысил среднего значения по России, то речь идет об «очень низком» уровне развития предпринимательства в регионе.

Таким образом, регионы России по уровню развития предпринимательской деятельности можно типологизировать следующим образом (см. табл. 2). 


\section{Типология регионов по уровню развития предпринимательской деятельности}

\begin{tabular}{|c|c|c|c|}
\hline № & Тип региона & \multicolumn{2}{|c|}{ Регионы, входящие в состав группы } \\
\hline 1 & $\begin{array}{l}\text { С высоким уровнем } \\
\text { развития предприни- } \\
\text { мательской деятель- } \\
\text { ности }\end{array}$ & $\begin{array}{l}\text { г. Москва } \\
\text { г. Санкт-Петербург } \\
\text { Краснодарский край } \\
\text { Республика Татарстан }\end{array}$ & $\begin{array}{l}\text { Пермский край } \\
\text { Самарская область } \\
\text { Красноярский край }\end{array}$ \\
\hline 2 & $\begin{array}{l}\text { С достаточным } \\
\text { уровнем развития } \\
\text { предпринимательской } \\
\text { деятельности }\end{array}$ & $\begin{array}{l}\text { Московская область } \\
\text { Ростовская область } \\
\text { Республика Башкортостан } \\
\text { Нижегородская область } \\
\text { Ханты-Мансийский } \\
\text { автономный округ - Югра }\end{array}$ & $\begin{array}{l}\text { Тюменская область } \\
\text { Челябинская область } \\
\text { Иркутская область } \\
\text { Свердловская область }\end{array}$ \\
\hline 3 & $\begin{array}{l}\text { Со средним уровнем } \\
\text { развития предприни- } \\
\text { мательской деятель- } \\
\text { ности }\end{array}$ & $\begin{array}{l}\text { Воронежская область } \\
\text { Ленинградская область } \\
\text { Ямало-Ненецкий } \\
\text { автономный округ }\end{array}$ & \\
\hline 4 & $\begin{array}{l}\text { С низким уровнем } \\
\text { развития предприни- } \\
\text { мательской деятель- } \\
\text { ности }\end{array}$ & $\begin{array}{l}\text { Волгоградская область } \\
\text { Республика Дагестан } \\
\text { Сахалинская область } \\
\text { Оренбургская область }\end{array}$ & $\begin{array}{l}\text { Приморский край } \\
\text { Кемеровская область } \\
\text { Новосибирская область }\end{array}$ \\
\hline 5 & $\begin{array}{l}\text { С очень низким } \\
\text { уровнем развития } \\
\text { предпринимательской } \\
\text { деятельности }\end{array}$ & $\begin{array}{l}\text { Белгородская область } \\
\text { Брянская область } \\
\text { Владимирская область } \\
\text { Ивановская область } \\
\text { Калужская область } \\
\text { Костромская область } \\
\text { Курская область } \\
\text { Орловская область } \\
\text { Рязанская область } \\
\text { Смоленская область } \\
\text { Тамбовская область } \\
\text { Тверская область } \\
\text { Тульская область } \\
\text { Ярославская область } \\
\text { Липецкая область } \\
\text { Республика Карелия } \\
\text { Республика Коми } \\
\text { Архангельская область } \\
\text { Вологодская область } \\
\text { Калининградская область } \\
\text { Мурманская область } \\
\text { Новгородская область } \\
\text { Псковская область } \\
\text { Республика Адыгея } \\
\text { Республика Калмыкия } \\
\text { Астраханская область } \\
\text { Республика Ингушетия } \\
\text { Кабардино-Балкарская } \\
\text { Республика } \\
\text { Республика Саха (Якутия) }\end{array}$ & $\begin{array}{l}\text { Карачаево-Черкесская } \\
\text { Республика } \\
\text { Республика Северная } \\
\text { Осетия - Алания } \\
\text { Чеченская Республика } \\
\text { Ставропольский край } \\
\text { Республика Марий Эл } \\
\text { Республика Мордовия } \\
\text { Удмуртская Республика } \\
\text { Чувашская Республика } \\
\text { Кировская область } \\
\text { Пензенская область } \\
\text { Саратовская область } \\
\text { Ульяновская область } \\
\text { Курганская область } \\
\text { Республика Алтай } \\
\text { Республика Бурятия } \\
\text { Республика Тыва } \\
\text { Республика Хакасия } \\
\text { Алтайский край } \\
\text { Забайкальский край } \\
\text { Камчатский край } \\
\text { Хабаровский край } \\
\text { Амурская область } \\
\text { Магаданская область } \\
\text { Еврейская автономная } \\
\text { область } \\
\text { Чукотский автономный округ } \\
\text { Омская область } \\
\text { Томская область } \\
\text { Республика Крым } \\
\text { г. Севастополь }\end{array}$ \\
\hline
\end{tabular}

Примечание. Составлено авторами. 
Проведенный авторами анализ показал, что численность объектов региональной инфраструктуры варьируется от 1 до 116. Для проведения расчетов составлена вспомогательная таблица 3 на основе учета классификации регионов и данных о наличии инфраструктурных объектов в регионах.

$$
\begin{gathered}
\varphi^{2}=1,39-1=0,41 . \\
K_{\Pi}=\sqrt{\frac{0,41}{1,41}}=0,54-\text { связь средняя. } \\
K_{\mathrm{\Psi}}=\sqrt{\frac{0,41}{\sqrt{(5-1) \cdot(5-1)}}}=0,32-\text { связь средняя. }
\end{gathered}
$$

\section{Выводы}

Из проведенной типологии регионов видно, что наибольшую группу составляют регионы с очень низким уровнем развития предпринимательской деятельности.

Между показателем, характеризующим численность инфраструктурных объектов поддержки предпринимательской деятельности и показателями, характеризующими объемы инвестиций в предпринимательский сектор и оборотами предпринимательского сектора существует пусть не высокая, но статистически значимая связь.
Проведем анализ взаимосвязей методом ранжирования. В анализе социально-экономических явлений часто приходится прибегать к различным условным оценкам с помощью рангов. Среди непараметрических методов оценки тесноты связи наибольшее значение имеет ранговый коэффициент Спирмена. Этот коэффициент может быть использован для определения тесноты связи как между количественными, так и между качественными признаками при условии, если их значения упорядочены или проранжированы по степени возрастания (убывания). Для расчетов по коэффициенту корреляции рангов Спирмена по исходным данным, используемым авторами ранее, определим зависимость между показателями, характеризующими результативность предпринимательской деятельности и количеством региональных инфраструктурных объектов поддержки предпринимательской деятельности.

В результате мы получили следующие показатели:

$$
\rho_{x / y}=1-\frac{6 \cdot 105894}{87\left(87^{2}-1\right)}=0,35-\text { по показателю }
$$

«Инвестиции в основной капитал» (млн руб.);

$$
\rho_{x / y}=1-\frac{6 \cdot 107288}{87\left(87^{2}-1\right)}=0,22-\text { по показателю }
$$

\begin{tabular}{|c|c|c|c|c|c|c|}
\hline \multirow[t]{2}{*}{ Тип региона } & \multicolumn{5}{|c|}{$\begin{array}{l}\text { Численность объектов региональной инфраструктуры } \\
\text { поддержки предпринимательства в регионах России }\end{array}$} & \multirow[t]{2}{*}{ Сумма } \\
\hline & До 3 & От 4 до 7 & От 7 до 10 & От 10 до 15 & Более 15 & \\
\hline $\begin{array}{l}\text { С высоким уровнем } \\
\text { развития предпринима- } \\
\text { тельской деятельности }\end{array}$ & 0 & 2 & 1 & 2 & 2 & 7 \\
\hline $\begin{array}{l}\text { С достаточным уровнем } \\
\text { развития предпринима- } \\
\text { тельской деятельности }\end{array}$ & 3 & 3 & 0 & 2 & 2 & 10 \\
\hline $\begin{array}{l}\text { Со средним уровнем } \\
\text { развития предпринима- } \\
\text { тельской деятельности }\end{array}$ & 2 & 0 & 1 & 0 & 0 & 3 \\
\hline $\begin{array}{l}\text { С низким уровнем } \\
\text { развития предпринима- } \\
\text { тельской деятельности }\end{array}$ & 3 & 3 & 1 & 1 & 0 & 8 \\
\hline $\begin{array}{l}\text { С очень низким уровнем } \\
\text { развития предпринима- } \\
\text { тельской деятельности }\end{array}$ & 21 & 19 & 16 & 2 & 0 & 58 \\
\hline Сумма & 29 & 27 & 19 & 7 & 4 & \\
\hline
\end{tabular}

«Оборот организаций» (млрд руб.);

\section{Вспомогательная таблица для расчета коэффициентов Пирсона-Чупрова}

Примечание. Составлено авторами. 


$$
\rho_{x / y}=1-\frac{6 \cdot 88076}{87\left(87^{2}-1\right)}=0,2-\text { по показателю }
$$

«Число предприятий и организаций» (тыс.);

$$
\rho_{x / y}=1-\frac{6 \cdot 92284}{87\left(87^{2}-1\right)}=0,16-\text { по показателю }
$$

«Сальдированный финансовый результат» (млн руб.).

В связи с тем что коэффициент Спирмена может принимать любые значения в интервале $[-1 ;+1]$, следует говорить об отсутствии сильной взаимосвязи между вышеперечисленными показателями и численностью инфраструктурных объектов поддержки предпринимательства в регионах России. Оценим полученное нами эмпирическое значение коэффициента Спирмена, сравнив его с соответствующим критическим значением для заданного уровня значимости из таблицы критических значений коэффициента ранговой корреляции Спирмена. Для выборки с числом элементов $m=85$ и уровнем значимости $p=0,05$ критическое значение коэффициента Спирмена колеблется в интервале от 1,990 до 1,987 .

$t_{p}=0,35 \sqrt{\frac{85-2}{1-0,35^{2}}}=3,3$ - для первого значения; $t_{p}=0,22 \sqrt{\frac{85-2}{1-0,22^{2}}}=2-$ для второго значения; $t_{p}=0,2 \sqrt{\frac{83-2}{1-0,2^{2}}}=1,86$ - для третьего значения; $t_{p}=0,16 \sqrt{\frac{85-2}{1-0,16^{2}}}=1,47-$ для четвертого значения.

Абсолютные значения полученных нами коэффициентов в первом и втором случаях больше критического значения.

Однако в общем виде целесообразно сделать вывод о том, что на показатели развития предпринимательского сектора в регионах России оказывает ключевое влияние не численное значение инфраструктурных объектов, а их качественное предоставление услуг. Поскольку даже при наличии достаточного количества объектов поддержки предпринимательской деятельности в регионах не приходится говорить о высоком уровне развития предпринимательства, целесообразно сделать вывод о необходимости качественных преобразований в системе инфраструктурного обеспечения предпринимательской деятельности [3]. Но учитывая тот факт, что количественные показатели обеспеченности инфраструктурой для различных регионов рознятся, следует разрабатывать инструментарий и механизмы развития региональной инфраструктуры поддержки предпринимательской деятельности отдельно для регионов, обладающих достаточным количеством инфраструктурных объектов, и для регионов, испытывающих недостаток региональной инфраструктуры.

\section{ПРИМЕЧАНИЕ}

1 Федеральный закон от 24 июля 2007 г. № 209-Ф3 «О развитии малого и среднего предпринимательства в Российской Федерации».

\section{СПИСОК ЛИТЕРАТУРЫ}

1. Болтнев, А. М. Теоретические основы методологии исследования и прогнозирования развития региона / А. М. Болтнев, Е. Ю. Меркулова // Ученые записки ТРОВЭОР. - Тамбов : Изд-во ТГУ им. Г.Р. Державина, 2003. - Т. 6, вып. 2.

2. Колесниченко, Е. А. Генезис теорий управления региональными экономическими системами / Е. А. Колесниченко, И. Р. Ляпина // Социальноэкономические явления и процессы. - 2010. № 5 (21). - C. 52-58.

3. Направления совершенствования инфраструктурного обеспечения инвестирования инновационной деятельности предпринимателей в регионах России / Е. А. Колесниченко, Я. Ю. Радюкова, А. М. Пейков, И. Н. Якунина // Современные фундаментальные и прикладные исследования. 2016. - № 3 (22). - С. 203-210.

4. Официальный сайт Федеральной службы государственной статистики: http://www.gks.ru/.

5. Mechanisms of support of export-oriented small enterprises: the regional aspect / U. V. Busarina, S. S. Morkovina, S. V. Budkova, E. A. Kolesnichenko // Asian Social Science. - 2014. - Vol. 10, № 23. P. 95-101.

\section{REFERENCES}

1. Boltnev A.M., Merkulova E.Yu. Teoreticheskie osnovy metodologii issledovaniya i prognozirovaniya razvitiya regiona [Theoretical Fundamentals of Research Methodology and Forecasting the Development of the 
Region]. Uchenye zapiski TROVEOR [TROVEOR Academic Notes]. Tambov, Izd-vo TGU im. G.R. Derzhavina, 2003, vol. 6, iss. 2.

2. Kolesnichenko E.A., Lyapina I.R. Genezis teoriy upravleniya regionalnymi ekonomicheskimi sistemami [Genesis of Theories of Regional Economic Systems Management]. Sotsialno-ekonomicheskie yavleniya i protsessy, 2010, no. 5 (21), pp. 52-58.

3. Kolesnichenko E.A., Radyukova Ya.Yu., Peykov A.M., Yakunina I.N. Napravleniya sovershenstvovaniya infrastrukturnogo obespecheniya investirovaniya innovatsionnoy deyatelnosti predprinimateley v regionakh Rossii [The Directions of Improving the Infrastructure Investments of Innovative Activity of Businessmen in Russian Regions]. Sovremennyefundamentalnye $i$ prikladnye issledovaniya, 2016, no. 3 (22), pp. 203-210.

4. Ofitsialnyy sayt Federalnoy sluzhby gosudarstvennoy statistiki [Official Website of Federal State Statistics Service]. URL: http://www.gks.ru/.

5. Busarina U.V., Morkovina S.S., Budkova S.V., Kolesnichenko E.A. Mechanisms of support of exportoriented small enterprises: regional aspect. Asian Social Science, 2014, vol. 10, no. 23, pp. 95-101.

\section{Information About the Authors}

Aleksandr M. Peykov, Postgraduate Student, Department of Political Economy and Modern Business Processes, Tambov State University named after G.R. Derzhavin, Internatsionalnaya St., 33, 392000 Tambov, Russian Federation, dissovet@tsu.tmb.ru.

Yana Yu. Radyukova, Candidate of Sciences (Economics), Associate Professor, Head of Department of Finance and Banking, Tambov State University named after G.R. Derzhavin, Internatsionalnaya St., 33, 392000 Tambov, Russian Federation, radyukova68@mail.ru.

Elena A. Kolesnichenko, Doctor of Sciences (Economics), Professor, Head of Department of Human Resource Management, Tambov State University named after G.R. Derzhavin, Internatsionalnaya St., 33, 392000 Tambov, Russian Federation, ekolesnichenko@live.ru.

\section{Информация об авторах}

Александр Михайлович Пейков, соискатель кафедры политической экономии и современных бизнес-процессов, Тамбовский государственный университет им. Г.Р. Державина, ул. Интернациональная, 33, 392000 г. Тамбов, Российская Федерация, dissovet@tsu.tmb.ru.

Яна Юрьевна Радюкова, кандидат экономических наук, доцент, заведующая кафедрой финансов и банковского дела, Тамбовский государственный университет им. Г.Р. Державина, ул. Интернациональная, 33, 392000 г. Тамбов, Российская Федерация, radyukova68@mail.ru.

Елена Александровна Колесниченко, доктор экономических наук, профессор, заведующая кафедрой кадрового управления, Тамбовский государственный университет им. Г.Р. Державина», ул. Интернациональная, 33, 392000 г. Тамбов, Российская Федерация, ekolesnichenko @live.ru. 